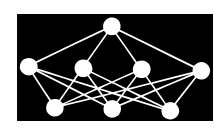

\title{
BIOMECHANICAL ANALYSIS \\ OF THE DUMMY RESPONSES IN CASE OF CHILD PEDESTRIAN/CYCLIST COLLISION WITH PASSENGER CAR
}

\author{
Zuzana Schejbalová*, Tomáš Mičunek*, Drahomír Schmidt*
}

\begin{abstract}
The safety of pedestrians and cyclists in traffic is justified especially in terms of prevention. This paper deals with the biomechanical analysis of load exerted on the child pedestrian and cyclist. In the case of cyclists, the impact configurations were chosen with respect to the statistical outputs (sudden enter the road or the case of non-giving way; the car front vs. the left side of the cyclists). Two tests were performed in the same configuration and nominal collision speed, the first one with a bicycle helmet and the second one without the helmet. The initial position of pedestrian was chosen with respect to the dummy degrees of freedom. Using the accelerometers in the head, chest, pelvis and knee of the dummy acceleration fields were detected, which are the child pedestrian and cyclist exposed during the primary and secondary collision. In addition, prediction diagnostics method implementation was discussed such as one possible solution of vulnerable road users harm reduction. In conclusion, the results are interpreted by values of biomechanical load and severity of potential injuries including kinematic and dynamic comparison.
\end{abstract}

Key words: Child cyclist, child pedestrian, passenger car, dynamic test, collision configuration, biomechanical load, accidents and losses minimization, prediction diagnostics

Received: September 5, 2013

Revised and accepted: December 10, 2013

\section{Introduction}

Pedestrians and cyclists are exposed to strongly incompatible impact within a collision with vehicle. The passive safety of cyclists colliding with a vehicle still remains, unlike the passive safety of pedestrians at the edge of interest. According

*Z. Schejbalová, T. Mičunek, D. Schmidt

Czech Technical University in Prague, Faculty of Transportation Sciences, Department of Forensic Experts in Transportation, Konviktská 20, Prague, Czech Republic 
to the World Health Organisation, 1.2 million of people die every year because of traffic accident (half of them are pedestrians, cyclists and motorcyclists) and approximately 50 million of people are injured [1]. The number of children fatalities is approx. 200,000 a year. In the Czech Republic there is noticed around 250 pedestrians' and cyclists' fatalities and 6,000 injuries every year [2]. The pedestrian safety is nowadays a very important criterion for vehicle safety evaluation. In the case of passive safety of cyclists the kinematic conditions are very different. Similar test methods related to passenger car front parts does not exist, while the cyclist's body comes into contact with other vehicle parts than the pedestrian of the same height. In frame of the basic research and expert verification tests, partial tests of the cyclist's collision with vehicle are carried out. The aim of these tests is to follow the kinematics of the whole collision; values of biomechanical loads are usually not detected. The legislation concerning cyclists is divided into regulations related to bicycles, bicycle helmets and rules for cyclists' behaviour in the road traffic. Testing of bicycle helmets is the only area that is screened in terms of passive safety of cyclists. According to EN 1078 bicycle helmets that are properly mounted on a dummy head are tested.

The following tests are performed: the helmet impact resistance while dropping on a flat surface or "curb", fixing buckle strength and ease of its release, the fixing efficiency of helmet polster and range of the visual field [3]. The main problem is that the bicycle helmets' wearing is not compulsory in many EU countries. In most cases it is compulsory only for children under 15 or 18 years of age.

\section{Material and Methodology}

The CTU in Prague, Faculty of Transportation Sciences, performed in frame of basic research a set of dynamic passive safety tests on a passenger car (M1 cat.) collision with a P6 dummy in the role of pedestrian and the cyclist. The goal of the
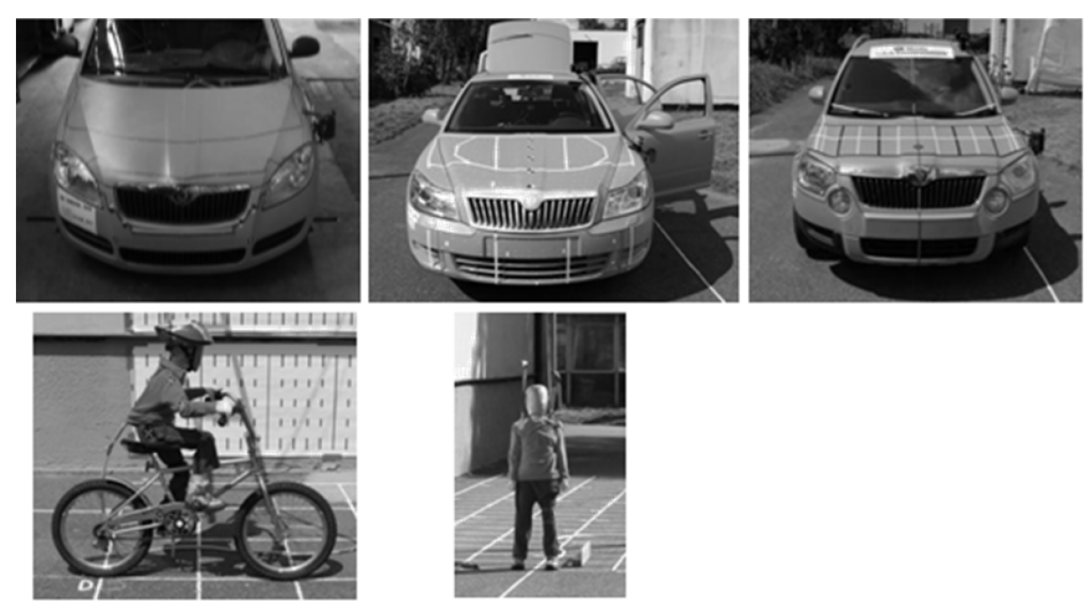

Fig. 1 From the left: Testing objects; Vehicles (M1 category) - Skoda Roomster, Skoda Octavia II, Skoda Yeti. Child cyclist, child pedestrian. 
Schejbalová Z. et al.: Biomechanical analysis of the dummy responses...

experimental work was to perform the series of full scale crash tests according to the matrix (see Tab. I). The tests were focused on vehicle front part, which are usually tested by impactors with respect to certified methodology 78/2009 ECE. For the full scale testing methodology the "six year old" dummy was used as the typical member of the most threatened group of the road traffic participants. The certified methodology 78/2009 ECE refers to the type-approval of motor vehicles with regard to the protection of pedestrians and other vulnerable road users, including cyclists. In terms of boundary conditions the limit case of conflict of child pedestrian (height $117 \mathrm{~cm}$, weight $22 \mathrm{~kg}$ ) and child bicyclist with a passenger car were tested [4].

There were 17 tests executed, in case of cyclist-vehicle test, two tests were implemented in the nominal collision speed $20 \mathrm{~km} / \mathrm{h}$ (with and without the helmet) and in a following collision configuration: the vehicle front part/the cyclist's side.

\begin{tabular}{|c|c|c|c|c|}
\hline & Skoda Roomster & Skoda Octavia & Skoda Yeti & Skoda Yeti \\
\hline & Year 2009 & Year 2010 & Year 2011 & Year 2012 \\
\hline $\begin{array}{l}\text { Child } \\
\text { pedes- } \\
\text { trian } \\
\text { (13 tests } \\
\text { in total) }\end{array}$ & $\begin{array}{l}\text { Impact speed } \\
10,20,30 \mathrm{~km} / \mathrm{h}, \\
2 \text { tests }\end{array}$ & $\begin{array}{l}\text { Impact speed } \\
10,20,30 \mathrm{~km} / \mathrm{h}\end{array}$ & $\begin{array}{l}\text { Impact speed } \\
10,20,30 \mathrm{~km} / \mathrm{h}\end{array}$ & $\begin{array}{l}\text { Impact speed } \\
20 \mathrm{~km} / \mathrm{h}, 3 \text { tests }\end{array}$ \\
\hline \multirow[t]{2}{*}{$\begin{array}{l}\text { Child } \\
\text { cyclist } \\
(4 \text { tests } \\
\text { in total })\end{array}$} & \multirow[t]{2}{*}{$\mathrm{x}$} & \multirow[t]{2}{*}{$\mathrm{x}$} & $\begin{array}{l}\text { Configuration 1: } \\
\text { with/without } \\
\text { helmet, from the } \\
\text { side, } 20 \mathrm{~km} / \mathrm{h}, \\
2 \text { tests }\end{array}$ & $\mathrm{x}$ \\
\hline & & & $\begin{array}{l}\text { Configuration } 2 \text { : } \\
\text { from the rear, } \\
30 \mathrm{~km} / \mathrm{h}\end{array}$ & $\begin{array}{l}\text { Configuration } 2 \text { : } \\
\text { from the rear, } \\
30 \mathrm{~km} / \mathrm{h}\end{array}$ \\
\hline
\end{tabular}

Tab. I Matrix of performed dynamic tests.

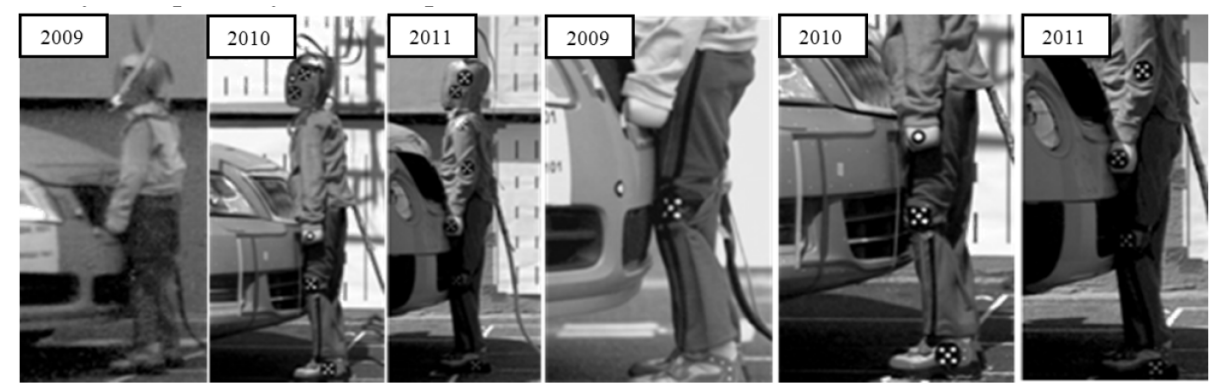

Fig. 2 Primary contact - overall (3 pictures from the left) and detailed view (3 pictures from the right). 


\section{Results}

\section{Analysis of primary contact - pedestrian}

\section{Phase of primary contact with Skoda Roomster (2009):}

- contact of upper leg vs. bumper (car ID area),

- knee vs. grille resp. its upper edge,

- pelvic area vs. mask with grille,

- pushing-up.

\section{Phase of primary contact Skoda Octavia II (2010):}

- contact of pelvic area vs. mask with grille - integrated in the hood - using hanging clearance of the hood, deformation of the mask,

- upper leg vs. bumper in car ID area,

- knee vs. lower grille in bumper.

\section{Phase of primary contact Skoda Yeti (2011):}

- contact of pelvic area with bonnet leading edge, upper leg contact with bumper in car ID area,

- knee contact with lower grille, lower leg vs. bumper lower edge with spoiler,

- abdominal area vs. mask with grille, chest contact with the hood trim.

Scheme in the Fig. 3 demonstrates differences in the vehicle front shape of used vehicles. Rhombus curve represents Skoda Roomster, cross curve represents Skoda Octavia II, solid curve represents Skoda Yeti. As it was mentioned above, the difference in the time course of the primary contact is caused by the vehicle frontal shape differences besides the initial dummy posture variation which will be discussed below. In case of contact with Skoda Roomster, the first contact occurs in dummy thigh area, in case of contact with other two vehicle types the contact occurs with pelvic area.

\section{Analysis of primary impact - cyclist}

\section{Configuration 1 - with/without helmet}

- bumper vs. left knee

- vehicle front mask vs. pelvic of the dummy

- hood vs. upper arm/shoulder

- hood vs. head of the dummy 
Schejbalová Z. et al.: Biomechanical analysis of the dummy responses...

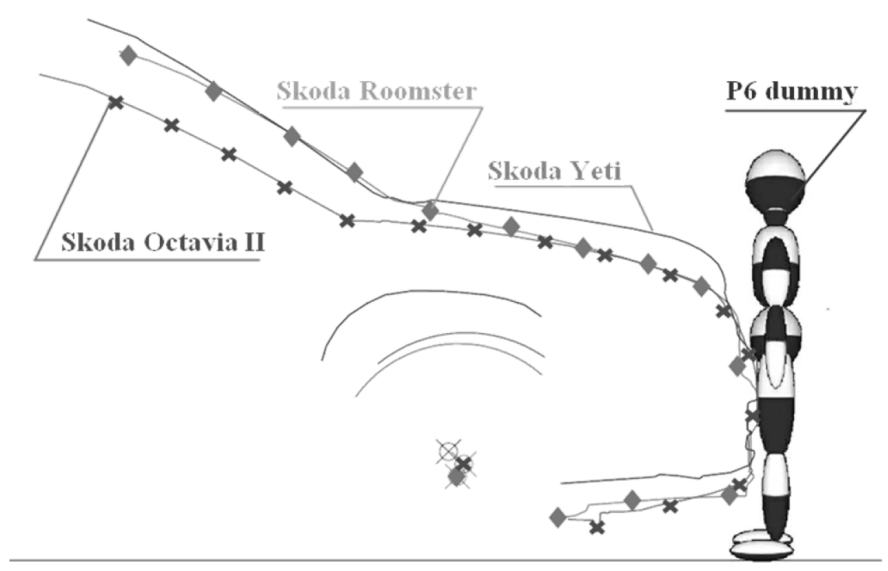

Fig. 3 Comparison of initial crash configuration with respect to vehicle front part geometry of Skoda Roomster, Skoda Octavia II, Skoda Yeti vs. P6 dummy.

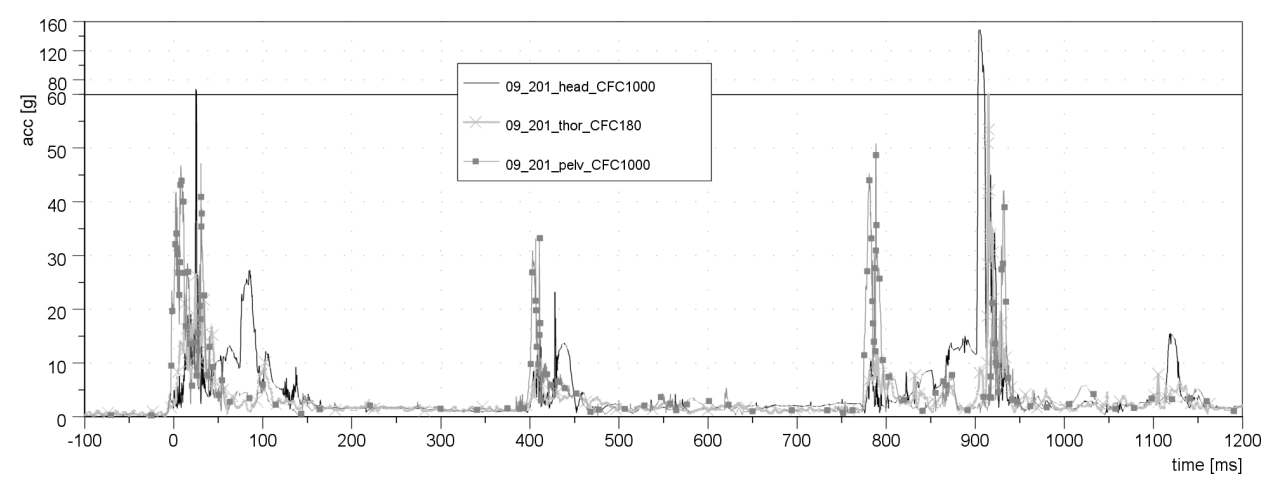

Fig. 4 Acceleration time course (head, thorax, pelvis) - Skoda Roomster.

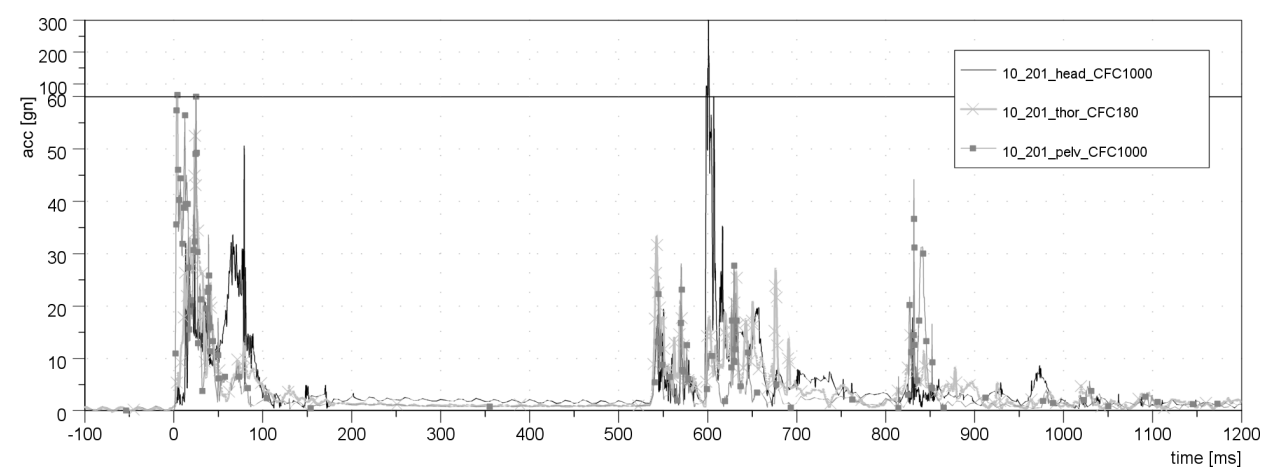

Fig. 5 Acceleration time course (head, thorax, pelvis) - Skoda Octavia II. 


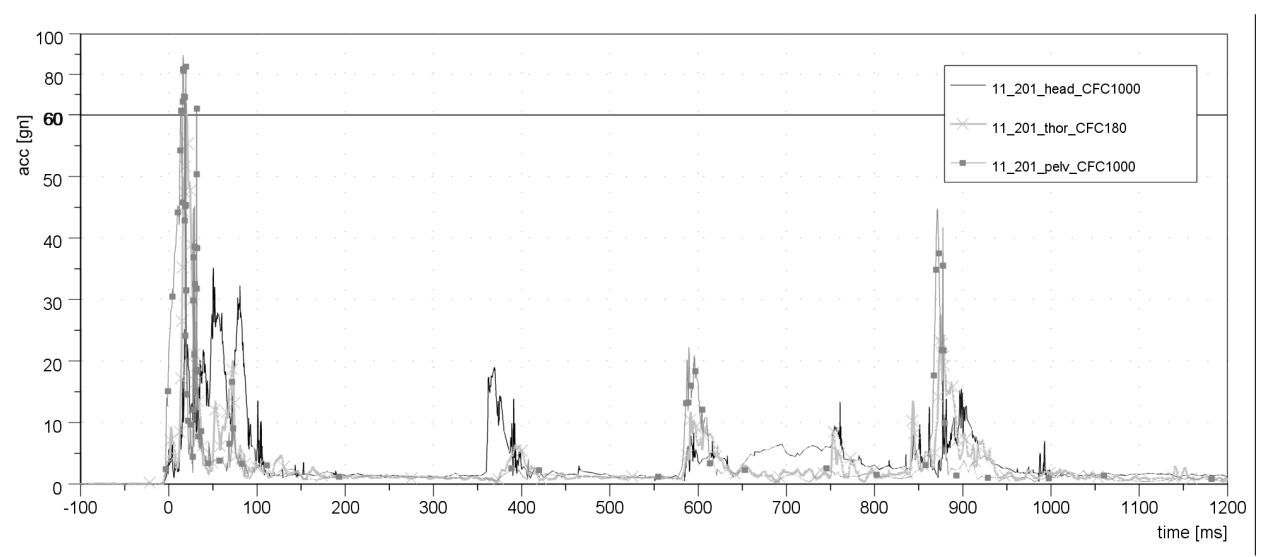

Fig. 6 Acceleration time course (head, thorax, pelvis) - Skoda Yeti.

\section{Configuration 2}

- vehicle front vs. rear wheel of bicycle

- vehicle front mask vs. pelvic of the dummy

- hood vs. back of the dummy

- hood vs. head of the dummy

\section{Discussion}

\section{Primary impact - pedestrian}

Head Values of the biomechanical criteria for the primary contact were not exceeded in any test. Measured values have been always below the threshold values. Such values would cause in a real accident: light injury in 35\% (bruises, grazes), moderate injury in $14 \%$ (e.g. yaw fracture), no injury in $45 \%$.[5]

Thorax It was confirmed (for the primary impact) that with the elevation of the bonnet frontal leading edge height (BLEH) the load (stress) to the thorax increases (it can be said, that more favourable load of the thorax was in the set of tests with Skoda Roomster, the least favourable in case of Skoda Yeti). During the tests in a nominal impact speed of $30 \mathrm{mph}$, the $\mathrm{a}_{3 \mathrm{~ms}}$ criterion it the test with a SUV car (Skoda Yeti) shows twice the values than in the other tests. It would mean $85 \%$ probability of pulmonary contusion, cardiac contusion and possibility of aortic rupture, while for a car with lower BLEH (the test sets of 2009 and 2010) the risk of these injuries is only cca $25 \%$ [5]. 


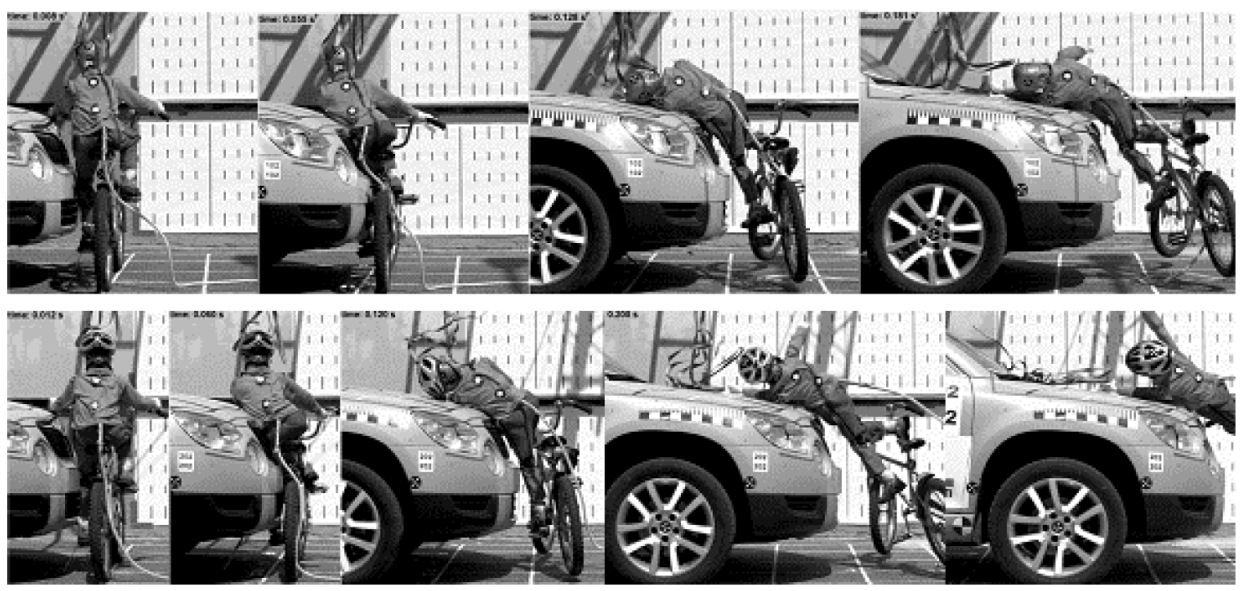

Fig. 7 Phase of primary contact in configuration 1.

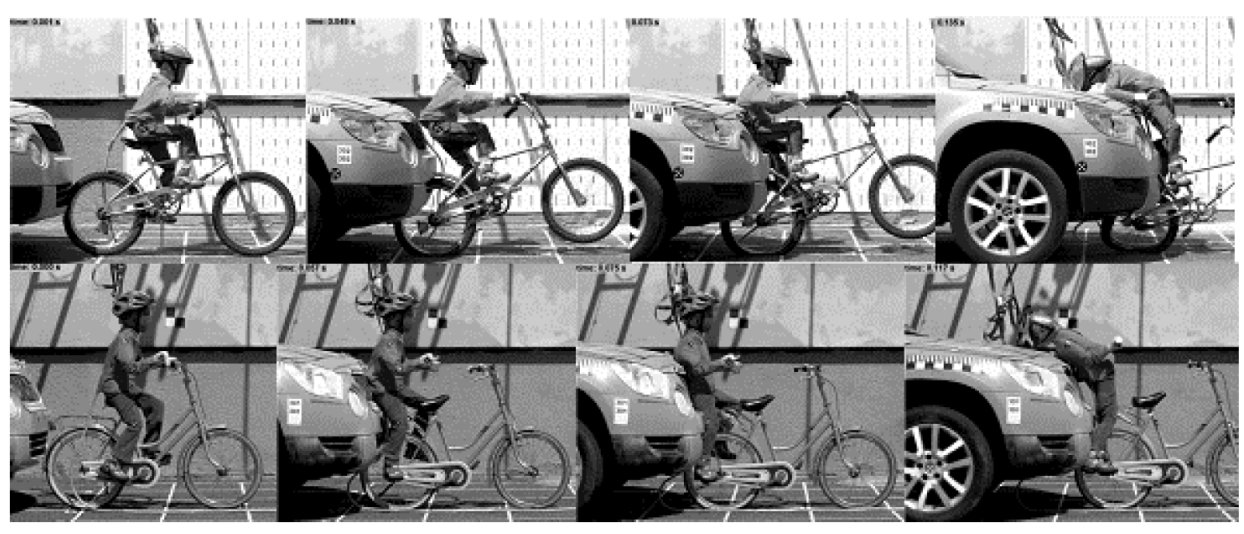

Fig. 8 Phase of primary contact in configuration 2.

Pelvis As mentioned in the previous chapter, the value of maximal acceleration ( $\mathrm{a}_{\max }$ criterion) acting on the pelvic region during the primary impact increases with the height of bonnet leading edge - it is given by the vehicle front end geometry.

Femur Measured values of the femur contact force for each nominal speed were comparable - regardless of the car. Lower values (about 10\%) were measured in the set of tests with Skoda Octavia II.

Knee Left knee instrumented, should be noted that a number of factors enter in this measurement: the order of contact places (points), knee flexion angle (even small) as an initial condition, difference in the load of both legs. It can be said that for the speeds from cca $20 \mathrm{~km} / \mathrm{h}$ the $\mathrm{a}_{\max }$ criterion was exceeded. 
The last set of tests pointed out to the negative impact of the higher front of the SUV category vehicle to the primary contact with a child pedestrian. The front end of these vehicles contacts both with the thigh, pelvic region and the thorax of the child pedestrian in a very short time interval. The thorax is aggressively affected even at speeds about $20 \mathrm{~km} / \mathrm{h}$.

\section{Repeatability and comparability of the test results - pedestrian} Primary impact

- Dummy positioning - strong correlation of results of measurements with a precision dummy positioning - the position of the lower limbs, upper limbs and angles between segments / joints (ie, the angle between the pelvis and thigh segments).

- The moment of road contact loss - the resultant acceleration are influenced mainly by the moment when the dummy loses contact with the ground - and by the location of the prevailing contact.

- Interdependence of dummy segments $\Rightarrow$ mutual transfer of forces / moments between particular segments and therefore mutual influence of signals.

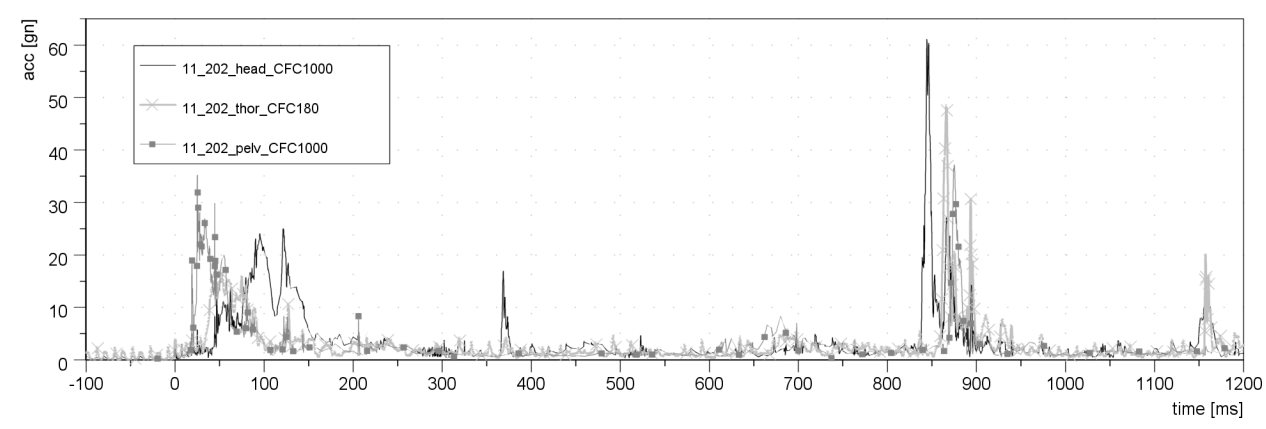

Fig. 9 Acceleration time course (head, thorax, pelvis) - configuration 1.

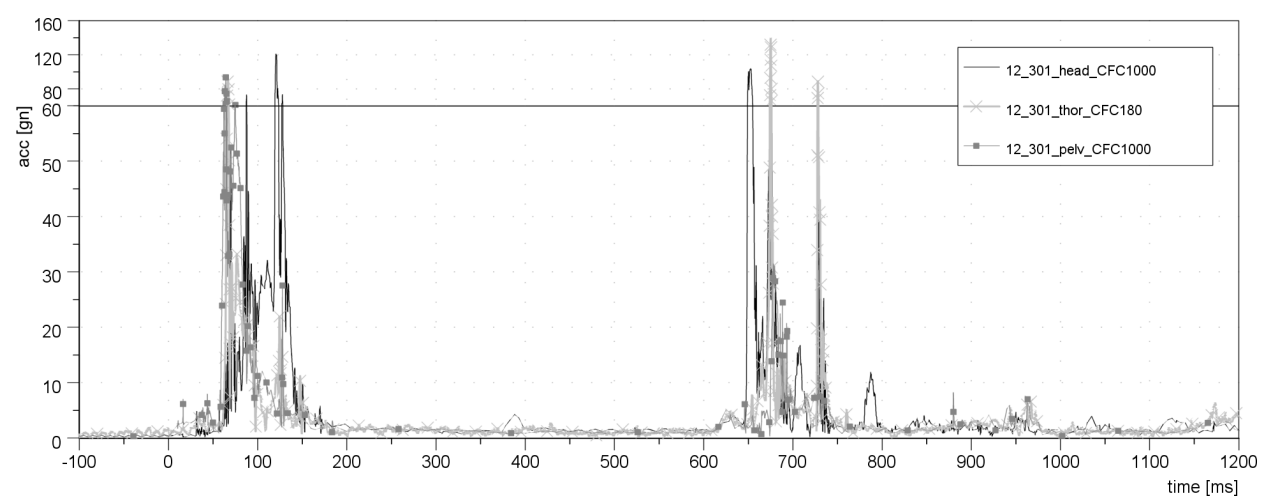

Fig. 10 Acceleration time course (head, thorax, pelvis) - configuration 2 - primary impact. 
Schejbalová Z. et al.: Biomechanical analysis of the dummy responses...

Influencing factors (according to the severity of impact)

- Tests accuracy - impact eccentricity - dummy rotation around the longitudinal axis $z$.

- Effect of cabling - in case of contact with legs causes dummy rotation, as well as the possibility of post - crash movement interference by "absorbing" the cable loop by the car front.

- Feet detention - eg. test 203 feet stuck under the bottom edge of the bumper cover.

- Impact speed variation.

\section{Discussion of the tests series - cyclist}

\section{Head injury}

- P6 dummy head in case of cyclist contacts the car hood (Skoda Yeti) approx. at the level of $\mathrm{WAD}^{1} 1200$ (in dependence on bicycle seat height).

- Performed tests in configuration 1 demonstrated especially the benefit of protective aids for cyclist, particularly protective helmet. This effect was significant within secondary collision. In test without helmet the child cyclist would be killed as a result of secondary collision which could be a significant threat to life, (probability approx. 16\%), would suffer injury severity AIS 5 (probability approx. 38\%), injury severity AIS 4 may occur in 28\%. As a result of secondary impact at test with the use of protective helmets for cyclists, the child cyclist would escape in $89 \%$ without injury, $8 \%$ of them would suffer light injuries such as abrasions and bruises $[5,6,7]$.

- Primary collision would not create any threat in the term of head injury occurrence.

- Note: The difference in HPC15 cannot be seen in the absence of helmets only. As was already reported in previous research reports concerning collisions with pedestrians, the secondary impact is the phenomenon with a high degree of uncertainty. On the video recordings there is evident a variation of secondary collision in both tests in the case of test with helmet there is a larger share of tangential force (pushing), which reduces the resulting biomechanical load. The initial conditions of both tests were selected for maximum comparability.

- Results of two tests in configuration 2 were also compared especially in terms of kinematics. Due to the different geometry of the sitting position (the position of the axis of the crank and handlebar), the centre of cyclist gravity is in a different height therefore there is a difference in a post-crash movement which can be expressed by different values of WAD of head contact with the bonnet (1250mm in test in 2011 and $1200 \mathrm{~mm}$ in test in 2012).

\footnotetext{
${ }^{1}$ WAD (wrap around distance) - means the distance from the ground to the point on the bonnet along the vehicle front structure.
} 
- In the test of configuration 2, the acceleration time course was measured, within the test in 2012 the 3ms criterion applied to the dummy head was exceeded, HPC criterion was not exceeded. The limit was exceeded during the contact between the head (ie. the head fitted with bicycle helmet) with hood. This result again points to the fact that the HPC criterion is not an appropriate criterion for a comprehensive evaluation of the severity of head injuries.

\section{Chest injury}

- The $3 \mathrm{~ms}$ criteria threshold for six-years-old child (55 g according to ECE 44) [8] was within the secondary impact slightly exceeded for tests in configuration 1, especially in the test No. 102. This value would cause the serious injury AIS $3+$ at least in $58 \%$ (lung contusion, respectively heart contusion with hemothorax or pneumothorax). In Test No. 202, the calculated $3 \mathrm{~ms}$ value is below the threshold, as well as the $3 \mathrm{~ms}$ values for the primary impact of the tests No. 201 and 202. The risk of AIS $2+$ injury is $10 \%$, respectively $17 \%[5,6,7]$.

- The test No. 301 in configuration 2 represent for the child cyclist risk of AIS $3+$ injury in $46 \%$ (ie. the higher speed means lower biomechanical load than in the configuration 1) $[5,6,7]$.

\section{Pelvic area injury}

- The maximum acceleration limit $130 \mathrm{~g}$ was not exceeded in any of the performed tests.[9] The highest value $64.2 \mathrm{~g}$ was measured in configuration 2 within the primary impact, which is suspected to cause minor injury.

\section{Knee injury}

- The maximum acceleration limit of the knee $(170 \mathrm{~g})$ was not exceeded in any of the performed tests. [4] In configuration 1 we can expect a slight crushing of joint. In configuration 2 there occurs no contact with the vehicle; the maximum acceleration of $34.3 \mathrm{~g}$ does not create a substantial risk of injury.

\section{Discussion of prediction diagnostics method implementation}

The results of this work show the need of the implementation of full-scale tests at the level of basic research for the needs of car manufacturers and certification methodology. Future development in certification process consists in implementation of highly biofidelic impactors and virtual models. Based on the results of this work we can suggest the extension of the existing impactor methodology by the impactor test of child thorax to vehicles with higher bonnet leading edge (detection of acceleration and deformation) for at least monitoring purposes.[10] Due to the 
limited physical options of vehicle is an element of active bonnet and airbag for pedestrians a significant improvement of the level of passive safety of pedestrians. These systems are able to "slow down" the movement of pedestrian/cyclist over a distance which means lower biomechanical load especially for pedestrian/cyclist head. Currently the active safety elements are activated by signals detected on the front bumper. The time interval between the decision algorithm and the full activation of the system (e.g. the airbags for pedestrians, achieving operating position of active bonnet) is determined by the moment of the first contact with the bumper and a head contact with the hood.

According to the performed tests in nominal speed $20 \mathrm{~km} / \mathrm{h}$ this interval reaches approximately $40 \mathrm{~ms}$ for child pedestrians (120cm height), For children cyclist the interval reaches approximately $120 \mathrm{~ms}$. These results must be perceived not just as a time interval for activation, but also as the boundary limit of the interval in which it is necessary to ensure the operating position of the active members. In the case of the tested with child pedestrian/cyclist it is $80 \mathrm{~ms}$ (the lower bound is extremely unfavourable). There must be provided sufficient stability of the system in time and positioning - for example, oscillations, setting up due to the shock effect of activation, airbag filling and working pressure maintenance.

In case of very short time for decision algorithm (for higher impact speed) it is necessary to implement active pre - crash systems which enable to shorten the activation time of the hood, airbag, crisis braking, but increase the risk of "misuse" activation.

If we demand the implementation of the most effective measures to protect pedestrians, we get already in the field of collision avoidance systems. These systems are able to affect the impact speed, which is the crucial parameter of this type of incompatible impact.

The main goal in all this research is to propose methods which can be used for decreasing of losses on health and lives of young pedestrians and cyclists. This can be done by the following two kinds of tools, which have to be used in harmony:

a) Mechanical prevention of impacts

b) Prediction of impact danger

Though various approaches can be used for realization of such prediction and accident prevention, one of the most efficient are these based on the methods of prediction diagnostics.

These methods are considerably well known, widely exploited in many areas of science and technology and successfully used also for problems solution of the reliability of human interactions with artificial systems, namely the vehicles. The above mentioned kind of traffic collisions belong evidently to this issue.

The principle of prediction diagnostics is generally based on the following approach involving these necessary steps:

- analysis of the most significant variables $\mathrm{P}$, influencing the considered system properties F,

- specification of the limits $\Delta \mathrm{F}$ of the considered system properties (functions) deviations from the required values, 
- prediction of the changes in these system properties (functions) caused by selected independent variables (namely the time) variances in their considered interval and of the danger that the actual deviations of $\mathrm{F}$ from required values are higher than $\Delta \mathrm{F}$,

- decision if there is a need for warning the system users or people in its environment that in certain horizon of independent variable changes the system operation can fail (i.e. if the actual deviations of $\mathrm{F}$ from required values are higher than $\Delta \mathrm{F})$,

- verification if the eventual warning was well understood, accepted and if respective safety operations were realized.

All these 5 steps of the general prediction diagnostics procedure have to be at each application done in time, satisfactorily in advance the predicted system operation failure or the accidental event. The well realized prediction diagnostic procedures represent the most powerful tool for losses prevention in general.

In case of application to the quick dynamic process one has to propose a specific modifications of the above mentioned prediction diagnostics methodology.

This proposal can consist of the estimation of intersection of two kinds of parameters sets characterizing respective collision situation. The first has to represent the vehicle parameters and its movement, the other the affected child pedestrian or cyclist and his/her movement.

Let denote the parameters belonging to the first set by $\mathrm{x}_{i}$ and these belonging to the other by $\mathrm{y}_{j}$. The number of both can be quite high, therefore for to be not loaded with the too high multidimensionality, the reasonable simple models are to be used. The long experience says that both $\mathrm{N}_{x}$ and also $\mathrm{N}_{y}$ is to be about 3 . Then, in the respective $\mathrm{X}$ and $\mathrm{Y}$ model space can be investigated the boundaries $\mathrm{R}_{x}$ and $\mathrm{R}_{y}$, in which the vehicle and body has to be before collision.

In standard tasks of prediction diagnostics one usually investigates the movement of respective system representing vector of parameters and asks if and probably when it can intersect the boundaries the region of acceptable system function. The movement of this vector along some trajectory (life curve) inside the region of acceptability can be considerably long.

In the case of vehicle - pedestrian or cyclist collision the situation is other. The time interval in which such event runs is considerably short, often significantly below $\mathrm{T}_{a}=0.5 \mathrm{~s}$. Therefore also the dynamics of the whole event must be considered. Therefore one possibility for probability of injury decrease can be seen in $\mathrm{T}_{a}$ prolonging, e.g. by the use of very short time prediction of collision probability by short distance warning tools e.g. radars etc. The time interval, though short, gained by such early warning could be used either for total collision prevention or at least for minimizing the secondary losses caused due very fast safety tools activation.

\section{Conclusion}

The aim of this study was to assess the suitability of existing testing methodology for passive safety of vulnerable road users in case of accident with a passenger 
car on the child population. Processed topic includes more than five-year period, starting with the analysis of real cases supported by national and global accident statistics. Selected methodology of full-scale tests with dummies representing a six-year old kids population was performed to determine the level of biomechanical loads selected segments of the dummy. The matrix of crash tests of different types vehicles with child pedestrians and cyclists, including methodology of data collection and documentation was designed.

The implementation of these tests revealed that the contact with the vehicle at impact speeds up to $30 \mathrm{~km} / \mathrm{h}$ is not as serious regarding to consequences for the child pedestrian as the contact with the ground. Child pedestrian is within the collision with the vehicle generally exposed to bigger biomechanical load compared to child cyclist. The main reason for that is that in case of child pedestrian there is a direct contact of the knee - chest area with the front grille of vehicle.

In a contrary, the impact with child cyclist includes greater proportion of sliding on the hood surface due to the higher centre of gravity.

The impact location of head of child pedestrians and cyclists in tested configurations is consistent with 78/2009 EC. Criterion for evaluating the level of biomechanical load of the head (HPC) based on a calculation of the time course of the resulting linear acceleration appeared to be biased for several times, especially in comparison with high speed recording of the dummy post-crash movement. For a comprehensive assessment of biomechanical load it is necessary to detect the angular acceleration of the head, particularly in the case of secondary impact, as well as the forces and moments in the cervical spine.

The geometry of the vehicle front part has a significant impact especially on the biomechanical load of thorax and pelvis, which can be demonstrated in the case of a test with a compact SUV Skoda Yeti at a speed around $30 \mathrm{~km} / \mathrm{h}$ with approx. doubled values of biomechanical load of chest and by $30 \%$ pelvic load increase. In the case of lower limbs load, knee acceleration limit was exceeded even at speeds of around $20 \mathrm{~km} / \mathrm{h}$ regardless of the type of collision partner. Measured contact forces acting on the bending of the femur exceed the numerical limit at impact speed of about $30 \mathrm{~km} / \mathrm{h}$.

Tests with cyclists in configuration 1 definitely confirmed a positive effect of bicycle helmet. The need for the use of bicycle helmets arose from the secondary impact result. Biomechanical load of cyclist head in configuration 1 is equal to the load of the head of pedestrian; the biomechanical load of other segments of the pedestrian body is about doubled in comparison to the cyclist.

From the sensitivity analysis was possible to formulate effects of various factors on the course of the test, including the result acceleration of the particular segments and their mutual interaction. These findings refer to difficulties in unification of initial conditions in case of full-scale tests, and therefore it is obvious the introduction of impactor testing methodology for the purpose of vehicles certification is obvious. In case of SUV vehicles the biomechanical load of thorax and pelvic pelvis is critical at lower impact speed. These body regions are not taken into account in impactor methodology.

The performed crash tests confirmed that the secondary impact represents higher risk for child pedestrian/cyclist than the contact with the vehicle. The recommendation how to protect vulnerable road user against the consequences of 
this incompatible collision arises from the theory how to fix the mass of pedestrian with the car body after collision. As the first approach we are able to formulate boundary conditions for such active system based on the performed crash tests experience.

In further work the author team hopes to propose the approach to necessary modification of the prediction diagnostics methodology so that it can represent the base for such in time warning and collision prevention.

This conclusion is generally valid, but it would require more detailed research in technical solution measures. Nevertheless the reached experimental data can be taken as good necessary base for this.

\section{Acknowledgement}

This contribution was supported by: MSM6840770043, Skoda Auto,a.s., TÜV SÜD Czech s.r.o., A.L.C.Z. a.s.

\section{References}

[1] World Report on Road Traffic Injury Prevention, World Health Organisation, 2004 http://whqlibdoc. who.int/publications/2004/9241562609.pdf

[2] Statistics of the road accidents in the Czech Republic from Police http://www.policie.cz/clanek/statistika-nehodovosti-178464.aspx

[3] European Standard EN 1078 "Helmets for pedal cyclists and for users of skateboards and roller skates"

[4] Regulation (EC) No 78/2009 of the European Parliament and the Council of 14 January 2009 on the type-approval of motor vehicles with regard to the protection of pedestrians and other vulnerable road users, amending Directive 2007/46/EC and repealing Directives 2003/102/EC and 2005/66/EC

[5] Proposed Dummies, Injury Criteria, And Other Changes - proposed changes for FMVSS 213 - PRASAD/MERTZ Injury risk curves http://www.nhtsa.dot.gov/Cars/rules/rulings/CPSUpgrade/CPSRevise/PRE/chapter3.html

[6] Abbreviated Injury Scale, 1990 Revision, Update 98 http://www.trauma.org/archive/scores/iss.html

[7] European New Car Assessment Programme Assessment Protocol - Pedestrian Protection http://www . euroncap.com/Content-Web-Page/fb5e236e-b11b-4598-8e20 3eced 15 ce 74 e/protocols.aspx

[8] ECE Regulation No. 44 - "Uniform Provisions Concerning the Approval of Restraining Devices for Child Occupants of Power-Driven Vehicles ('Child Restraint Systems')" http://www . unece.org/fileadmin/DAM/trans/main/wp29/wp29regs/r044r2e.pdf

[9] FMVSS Regulations http://www.crash-network. com/Regulations/FMVSS/fmvss.html

[10] Kvášová, A., Frydrýn, M., Marek, Z.: Stet osobního automobilu s dtským chodcem - zkoušky a analýza In: Soudní inženýrství. 2011, Vol. 22, No. 2-3, pp. 130-138. ISSN 1211-443X. 